\title{
PERCEIVED INDOOR AIR QUALITY AND PSYCHOSOCIAL WORK ENVIRONMENT IN OFFICE, SCHOOL AND HEALTH CARE ENVIRONMENTS IN FINLAND
}

\author{
KATJA TÄHTINEN ${ }^{1,2}$, JOUKO REMES ${ }^{1}$, KIRSI KARVALA ${ }^{1}$, KARI SALMI ${ }^{1}$, MARJAANA LAHTINEN, ${ }^{1}$ \\ and KARI REIJULA ${ }^{1,3}$
}

${ }^{1}$ Finnish Institute of Occupational Health, Työterveyslaitos, Finland

Healthy Workspaces

${ }^{2}$ Aalto University, Aalto, Finland

Department of Civil Engineering

${ }^{3}$ University of Helsinki, Helsinki, Finland

Medical Faculty, Department of Public and Occupational Health

\begin{abstract}
Objectives: The study examined the extent and prevalence of perceived indoor environment-related (IE-related) symptoms environmental complaints and psychosocial work environmental factors in Finnish office, school and health care environments. Material and Methods: The data were collected from non-industrial workplaces (N = 455) in 2011-2012 and 2015-2017 using the Finnish Institute of Occupational Health's Indoor Air Questionnaire (IA Questionnaire). Suspicion of IE-related problems was reported in 59\% of workplaces. The data consisted of 28826 employees' responses. Results: The employees reported symptoms and environmental discomfort in office environments less often than in school or health care environments. The most often reported IE-related complaints were stuffy air (39\% of respondents), dry air (34\%) and insufficient ventilation $(33 \%)$. The most often reported symptoms were irritation of the nose (27\% of respondents), irritation of the eyes (26\%), and hoarse or dry throat $(24 \%)$. The results showed differences between the perceived IE in office, school and health care environments. Conclusions: Compared to earlier findings, the most often perceived IE-related symptoms and complaints have increased in Finnish health care environments. The office employees' perceptions of psychosocial work environment remained fairly unchanged whereas health care personnel more often assessed their psychosocial environment as positive compared to previous reports. Instead of exact reference values, comparing the results of IA Questionnaires with the distributions and mean values of the results of this study may be more informative for those striving to solve IE-related problems. The presented distribution and mean values of perceived symptoms, environmental complaints and psychosocial work environment might help to relate the results to other workplaces. This, in turn, might increase the understanding that IA Questionnaire results are influenced by many factors. The results presented can be used as new reference material when interpreting the results of IA Questionnaires in office, school and health care environments. Int J Occup Med Environ Health. 2020;33(4):479-95
\end{abstract}

Key words:

Indoor Air Questionnaire, school, health care, perceived indoor environment, reference material, office

Received: October 16, 2019. Accepted: March 9, 2020.

Corresponding author: Katja Tähtinen, Finnish Institute of Occupational Health, Healthy Workspaces, P.O. Box 18, Työterveyslaitos 00032, Finland (e-mail: katja.tahtinen@ttl.fi). 


\section{INTRODUCTION}

\section{Perceived indoor environment -}

a complex mix of different factors

In Finland there has been extensive, long-term concern about indoor air quality (IAQ) and its impact on health, specifically in non-industrial workplaces. However, although IAQ problems are common in Finland, their prevalence or detected IAQ is not exceptional in comparison to other countries [1-5]. It is also known that indoor environment (IE) comfort influences satisfaction factors in different ways, depending on the country [6], location [4] and socio-cultural context [4].

According to Statistics Finland's Quality of Work Life Survey 2013 [7], more than 1 in 4 Finnish wage and salary earners are very satisfied with their workspaces. However, female wage and salary earners reported more noise and disruptions in their work environment than males [7]. The most often reported environmental factors were noise, too low or too high temperatures, insufficient ventilation, and dust [7]. According to the same study, the prevalence of different types of experiences is not, in all cases, directly related to the reported environmental factors. Thus, perceived and measured IAQ may be different [8-10].

Several studies have found that perceived IAQ varies according to building types [1,4]. Different building-related factors [4,11-13], individual factors [12,14], the psychosocial environment [10,15-17], the questionnaire information itself [18], and worries [19] have been found to affect perceived IAQ. A previous study found that indoor environmental satisfaction is a flexible, subjective experience, as are cultural factors [6]. Based on earlier studies $[8-10,15,16]$, problem-solving should take account of related contextual factors, such as the condition of the building, perceived IAQ, psychosocial work environment, individual factors, and problem-solving measures. One problem-solving method is to use the Indoor Air Questionnaire (IA Questionnaire) to ask employees about their experiences of IE and the psychosocial work envi- ronment. Indoor Air Questionnaires are a relevant part of the IE problem-solving process and are a well-established and commonly used tool for monitoring perceived IE and psychosocial work environment in Finnish workplaces. Indoor Air Questionnaires are primarily intended for health care professionals, but multi-professional teams can also widely use their results as part of problem-solving.

\section{Office environments}

In the 1980 s, WHO reported that up to $30 \%$ of employees complained of building-related symptoms [20]. In the 1990s, Andersson [18] reported reference values based on the results of Örebro MM-40 Indoor Climate Questionnaire (Örebro MM-40) surveys in 9 non-industrial buildings. The most prevalent IE-related complaints were dry air (20\% of respondents), stuffy air (10\%) and dust or dirt $(10 \%)$, and the most prevalent symptoms were fatigue (10\% of respondents), irritated/runny nose (9\%) and irritation of the eyes and itching scalp or ears $(6 \%)$ [18]. In 2004, Reijula et al. [21] reported the Örebro MM-40 results of 11154 respondents in 122 non-industrial workplaces. The most prevalent IE-related complaints were dry air (35\% of respondents), stuffy air (34\%), draft (22\%), too high room temperature (17\%) and unpleasant odors (17\%) [21]. The most prevalent IE-related weekly symptoms were irritated/runny nose (20\% of respondents), irritation of the eyes (17\%), fatigue (16\%), irritation of the skin on the hands (15\%) and hoarse throat (14\%) [21].

A study published in 2015 [12] on indoor climate comfort in Italian offices revealed that $>31 \%$ of employees reported symptoms and $65 \%$ had made IE-related complaints. In the 2000s, office workplace studies reported (using Örebro MM-40) general IE-related complaints of varying temperatures (21\% of respondents) [12], dry air $(9 \%)$ [12] and stuffy air (8\%) [12], while IE-related weekly symptoms were upper respiratory symptoms (30\% of respondents) [22], lower respiratory symptoms (25\%) [22] and eye irritation (48\%) [22]. 


\section{School environments}

In schools, teachers reported more IE-related symptoms than pupils $[18,23]$. There is some evidence of teachers' increasing respiratory symptoms in classrooms with too high or too low IA relative humidity [24], poor building condition, and damp and mould exposures [25]. In previous studies in the USA, $72-84 \%$ of teachers reported nasal symptoms [25,26], 43\% asthma-like symptoms [25], $18-40 \%$ throat irritation [25,26], 4-33\% wheezing [25,26] and $30 \%$ lower respiratory symptoms [25]. In a Finnish follow-up study [27], the symptom prevalence (using Örebro $M M-40$ ) among the teachers was high before remediation of the buildings. Teachers' most often reported IE-related symptoms were hoarseness (93\% of respondents), rhinitis (74\%), dyspnea (37\%) coughing (30\%) and fatigue (27\%) before remediation of the buildings.

\section{Health care environments}

Employees in hospitals more often reported IE-related symptoms and complaints (using the Örebro MM-40-based questionnaire) than employees in offices in Finland [1]. Furthermore, employees more often reported IE-related symptoms and complaints in hospital buildings in need of repairs than in hospital buildings not requiring repairs [1]. According to the same study, the most common IE-related weekly complaints in hospitals were dry air $(46 \%$ of respondents), stuffy air (40\%), noise (30\%) and draft (27\%). The most common IE-related weekly symptoms were irritation of the nose ( $25 \%$ of respondents), irritation of the hands (24\%), irritation of the eyes $(23 \%)$ and fatigue $(21 \%)$ [1].

A recent study of Finnish hospital environments [2] found that the most prevalent IE-related symptoms (using Örebro MM-40) were irritated/runny nose (52\% of respondents), irritation of the eyes (46\%), irritation of the skin on the face (44\%) and fatigue and irritation of the skin on the hands $(43 \%)$. However, in this study [2], building investigation results did not explain the perceived IAQ-related symptoms. In the authors' earlier study [9], the results (using the Örebro MM-40based questionnaire) were very similar, such as the prevalence of symptoms of irritation of the nose ( $>40 \%$ of respondents), irritation of the eyes (>30\%) and irritation of the skin on the hands (>30\%) in Finnish hospital environments. The authors also deduced that extensive impurity sources in the premises are not always associated with the prevalence of perceived symptoms [9].

\section{Psychosocial work environment}

In former studies, psychosocial work environment has shown to be significantly associated with IAQ problems, IE-related symptoms and complaints [8,15,17], and thus it was also briefly surveyed in Örebro MM-40. In this respect, this questionnaire could be useful as a rough practical screening method for analyzing the role of psychosocial environment. Lahtinen et al. [15] stated in their study that $75 \%$ of respondents perceived their work as being often interesting, 72\% received help from their colleagues, $20 \%$ had too much work, and $35 \%$ were able to influence their working conditions in Finnish office environments. The earlier study of Finnish hospital environments [1] by the Finnish Institute of Occupational Health (FIOH) found that $82 \%$ of respondents perceived their work as being often interesting and stimulating, $78 \%$ often received help from their colleagues, $21 \%$ were often able to influence their working conditions, and $22 \%$ often had too much work to do.

\section{The aim of the study}

The aim of this study was to assess the prevalence of symptoms and environmental complaints related to IE and perceived psychosocial work environment in office, school and health care environments in Finland in the 2010s. Since IA Questionnaires (Örebro MM-40-based) are an established and commonly used tool in the IE problemsolving process in Finnish workplaces, the authors' aim 
was also to collect up-to-date reference material that can be used to interpret the results of the IA Questionnaires (Örebro MM-40-based) in office, school and health care environments.

\section{MATERIAL AND METHODS}

\section{Materials}

Since 1995, FIOH has used a standardized IA Questionnaire as a parallel tool with other methods to investigate IE-related problems in workplaces. Usually, someone from the workplace's occupational health care service contacts FIOH to investigate the extent, severity and probability of the IE-related problem at the workplace. Monitoring the state of perceived IE via a questionnaire is also a normal follow-up measure, for example, after IA-related repairs. In this study, the data were collected primarily from different workplaces a part of FIOH's customer services, and secondly through FIOH's research and development projects. The respondents were from different nonindustrial workplaces and different locations in Finland. The questionnaire was answered via the internet. The FIOH's's IA Questionnaire link was emailed to the participants. The email also contained a cover letter to explain the questionnaire's purpose and method, and information about the use of the results and personal data protection. Participation was voluntary. To ensure reliable results, the response rate had to be high. Therefore, both FIOH and the employer reminded the participants to answer to the questionnaire.

The data included 28826 IA Questionnaire responses from 2011-2012 and 2015-2017. This study used all the queries made by FIOH during these years. The background information revealed that workplaces either had suspected IErelated problems $(\mathrm{N}=16902$ [58.6\%]) or that the questionnaire was used for monitoring the state of perceived IE ( $\mathrm{N}=4244$ [14.7\%]). The data did not include information on the purpose of the questionnaire in the workplaces $(\mathrm{N}=7680$ [26.6\%]). In this study, the authors fo- cused on the overall data covering 28862 employees' responses. They also analyzed separately the responses from the workplaces monitoring the state of perceived IE $(\mathrm{N}=$ 4224). The mean response rate was $77 \%$, with a range of $43-100 \%$. As regards gender and age, $70 \%$ of respondents were women and mean age was 47.

The data included questionnaire responses from several work environments, 206 offices (57\% of responses), 122 schools (18\%) and 127 health care environments $(25 \%)$. The office workplaces were from the government sector $(39 \%)$, the public sector $(21 \%)$, the private sector $(34 \%)$ and other sectors $(6 \%)$. The schools were from the government sector (4\%), the public sector (93\%) and other sectors $(3 \%)$. The school workplaces included universities, elementary and high schools, and schools of applied sciences. The health care workplaces were from the government sector $(2 \%)$, the public sector $(75 \%)$, the private sector (19\%) and other sectors (4\%).

\section{Questionnaire}

The IA Questionnaire is based on Örebro MM-40 [18], modified slightly by FIOH in 2006-2008 [1]. It is divided into 4 parts and contains questions on:

1) the work environment,

2) work arrangements,

3) individual allergy history,

4) work environment-related symptoms.

In the first part, the work environment questions deal with draft, stuffy and dry air, insufficient ventilation, mould or other unpleasant odors, room temperatures, tobacco smoke, noise, dim light or reflections, and dust or dirt. In the second part, individual allergy history concerns past or present asthma, allergic rhinitis and atopic eczema. In the third part, the IE-related symptoms questions deal with fatigue, headache, feeling heavy-headed, concentration difficulties, fever or chills, irritation of the eyes, irritation of the nose, hoarse or dry throat, coughing, coughing at night, shortness of breath, wheezing, irritation of 
the skin on the face, irritation of the skin on the hands, muscular pain and joint pain.

In the first 3 parts, the questions have 3 response options: "yes, often," "yes, sometimes" and "no, never." The authors' study focused on the IE-related symptoms and environmental complaints that occurred weekly and the answer alternative "yes, often."

In the fourth part, the psychosocial work environment is evaluated using the following questions: "Do you regard your work as interesting and stimulating?" "Do you have too much work?" "Are you able to influence your working conditions?" "Do your fellow workers help you with work-related problems?" The response options are: "yes, often," "yes, sometimes," "no, seldom or rarely," "no, never."

To study perceived stress, a validated single-item measure of stress symptoms is used [28], "Stress means a situation in which a person feels tense, restless, nervous or anxious or is unable to sleep at night because his/her mind is troubled all the time. Do you feel this kind of stress these days?" The response options were: "not at all," "just a little," "some," "quite a lot," "very much." In the analyses, the authors combined the levels "not at all" and "some" and "just a little" into 1 level, and the levels "quite a lot," and "very much," into a single level.

\section{Statistical analyses}

For the statistical analyses, the authors used the SPSS 25.0 program. In the analyses, they calculated the confidence intervals for percentages based on normal distribution. The calculations also covered the distribution of responses separately for office, school and health care environments. Distribution values were calculated at the workplace level.

As this was a questionnaire-based study in which participation was voluntary and involved no intervention on individuals, according to the Finnish legislation it did not require handling by an ethics committee.

\section{RESULTS}

\section{Indoor environment-related complaints}

The IE-related complaints differed in office, school and health care environments (Table 1). The health care employees more often reported complaints related to stuffy air (55.7\% of respondents), dry air (49.9\%), insufficient ventilation $(47.7 \%)$, mould odor $(26.6 \%)$ and unpleasant odor $(30.5 \%)$ than the school or office employees (Table 1). The school employees more often reported complaints about noise (32.8\% of respondents) and dust or dirt $(20.2 \%)$ than the other groups. The office employees less often reported complaints about stuffy air $(30.0 \%$ of respondents), dry air (27.7\%), insufficient ventilation $(25.0 \%)$, draft $(16.7 \%)$ and dust or dirt (16.6\%) than the other groups (Table 1).

Table 2 presents data on the distribution of perceived IE-related weekly environmental complaints. The mean values in Table 1 are mostly within the range of 50th-75th percentile (Table 2).

Table 3 illustrates the percent mean values of employees' IE-related complaints in workplaces that were monitoring the state of perceived IE, for example, after IA-related repairs. In addition, IE-related complaints were common in these workplaces.

\section{Indoor environment-related symptoms}

The perceived IE-related symptoms differed in the office, school and health care environments (Table 1). The health care employees more often perceived, for example, symptoms of irritation of the nose (39.2\% of respondents), irritation of the eyes (37.8\%), hoarse or dry throat (33.8\%), fatigue $(25.9 \%)$, or feeling heavy-headed $(26.0 \%)$ than the other groups (Table 1). The school employees more often perceived symptoms of shortness of breath $(5.2 \%$ of respondents) and fever or chills (3.7\%) than the other groups (Table 1). The office employees less often perceived, for example, symptoms of irritation of the nose (21.5\% of respondents), irritation of the eyes (21.4\%), 


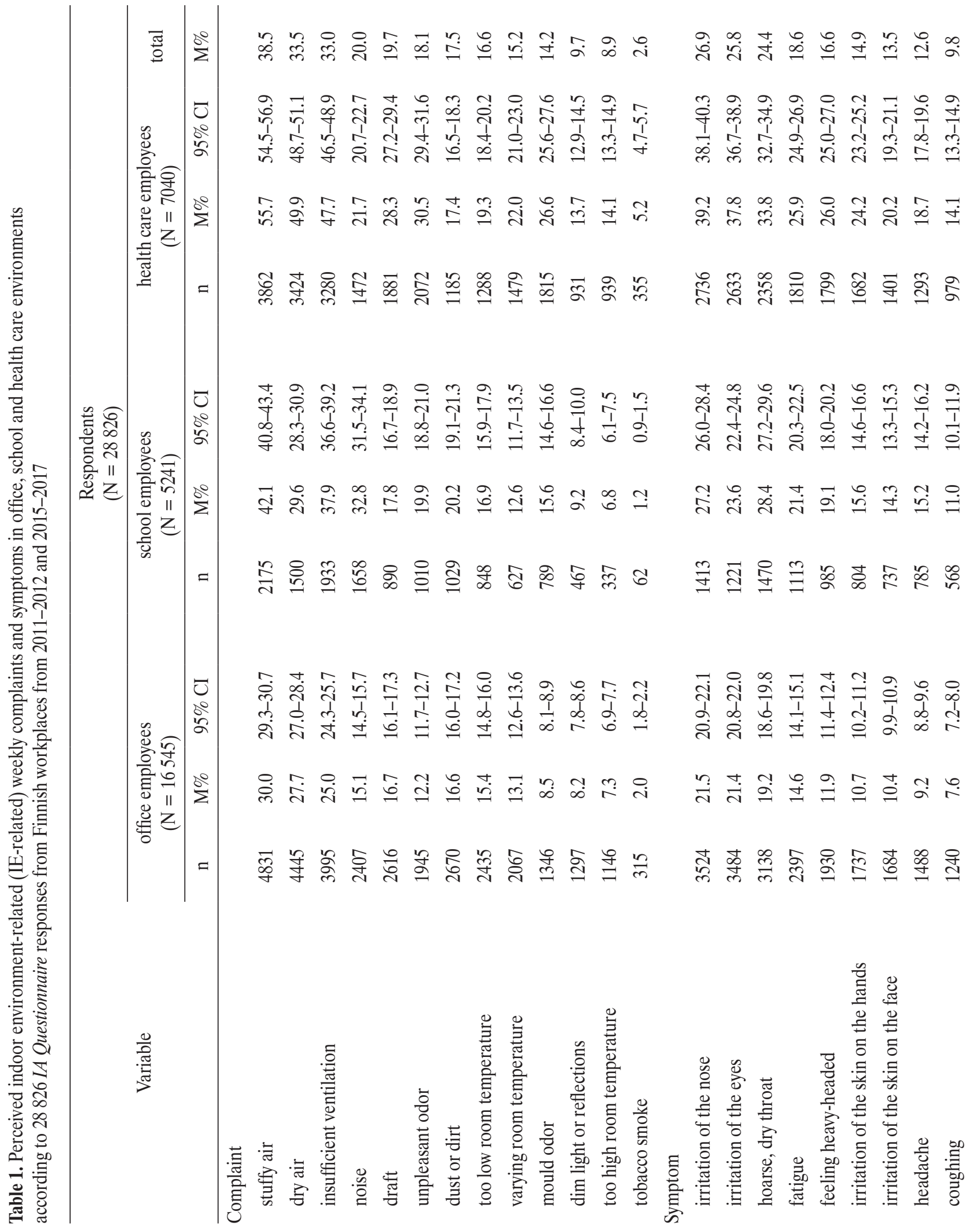




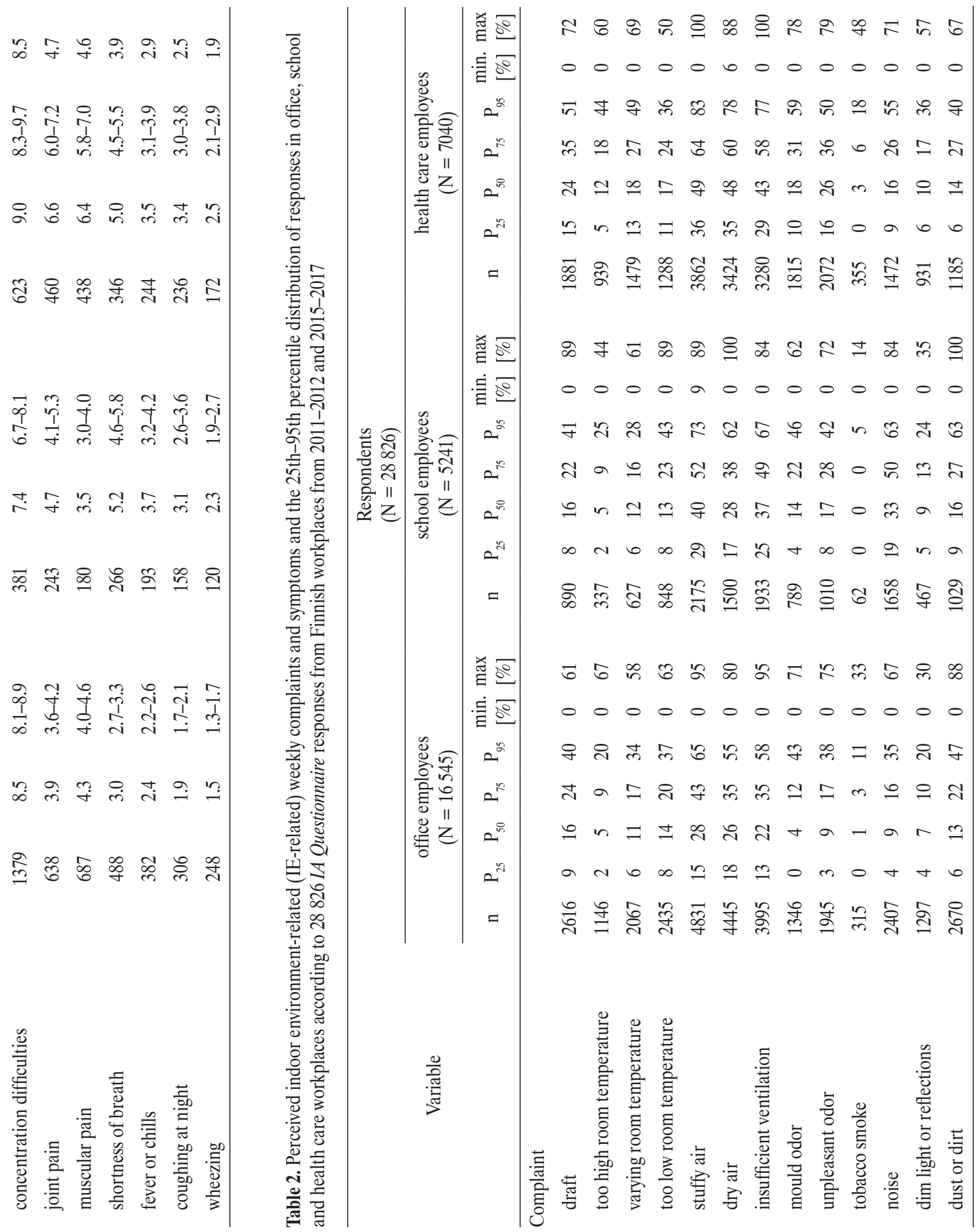




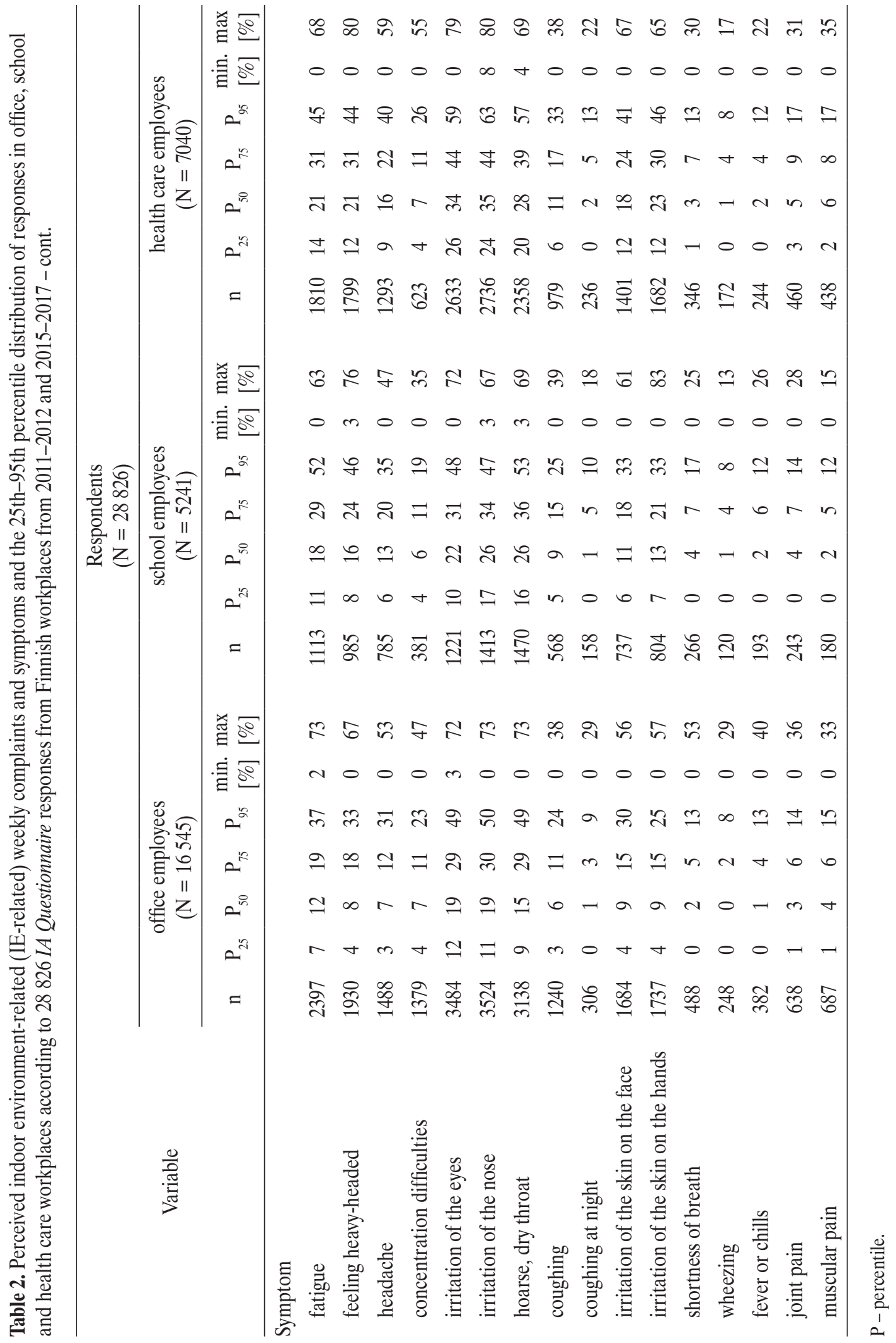




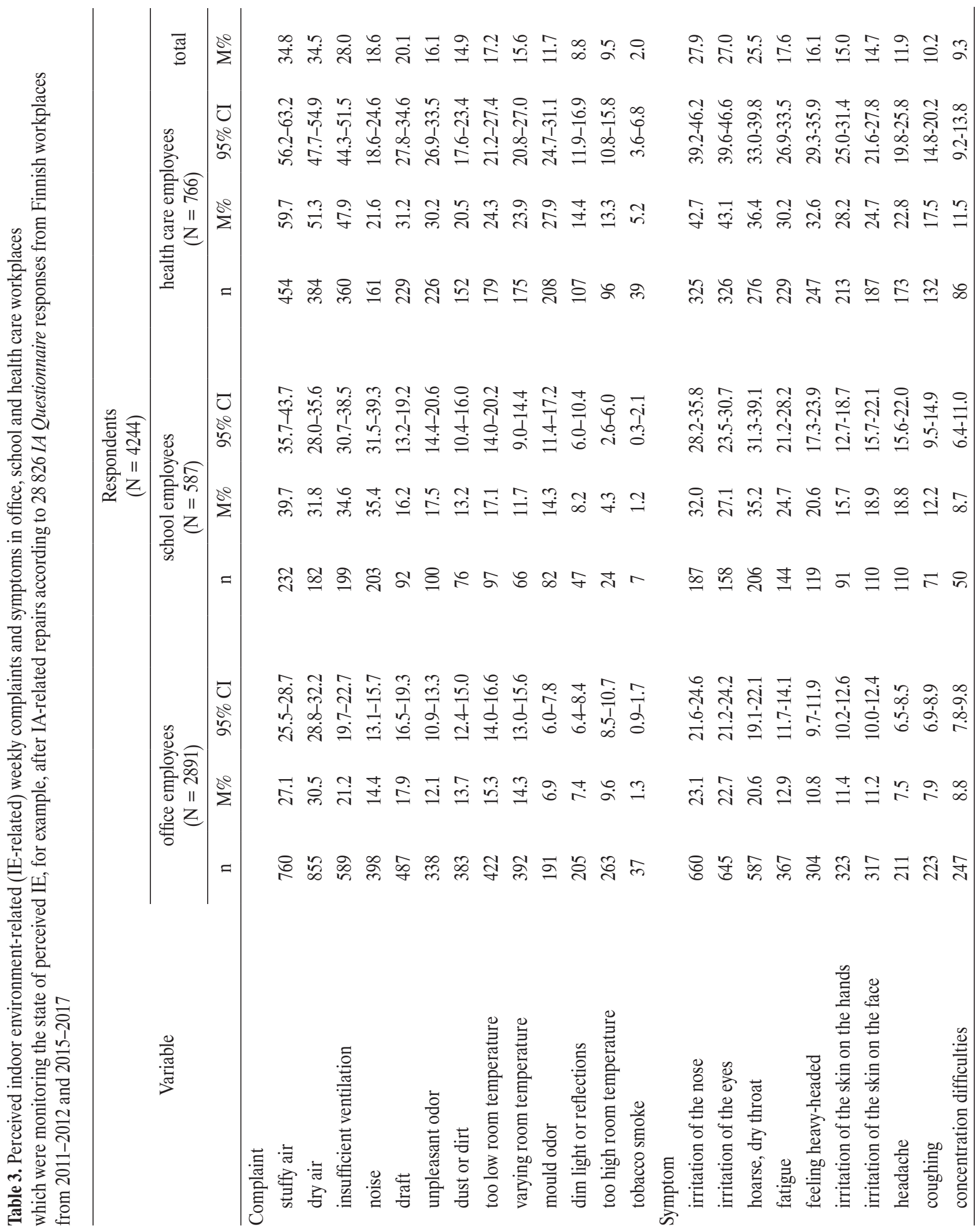




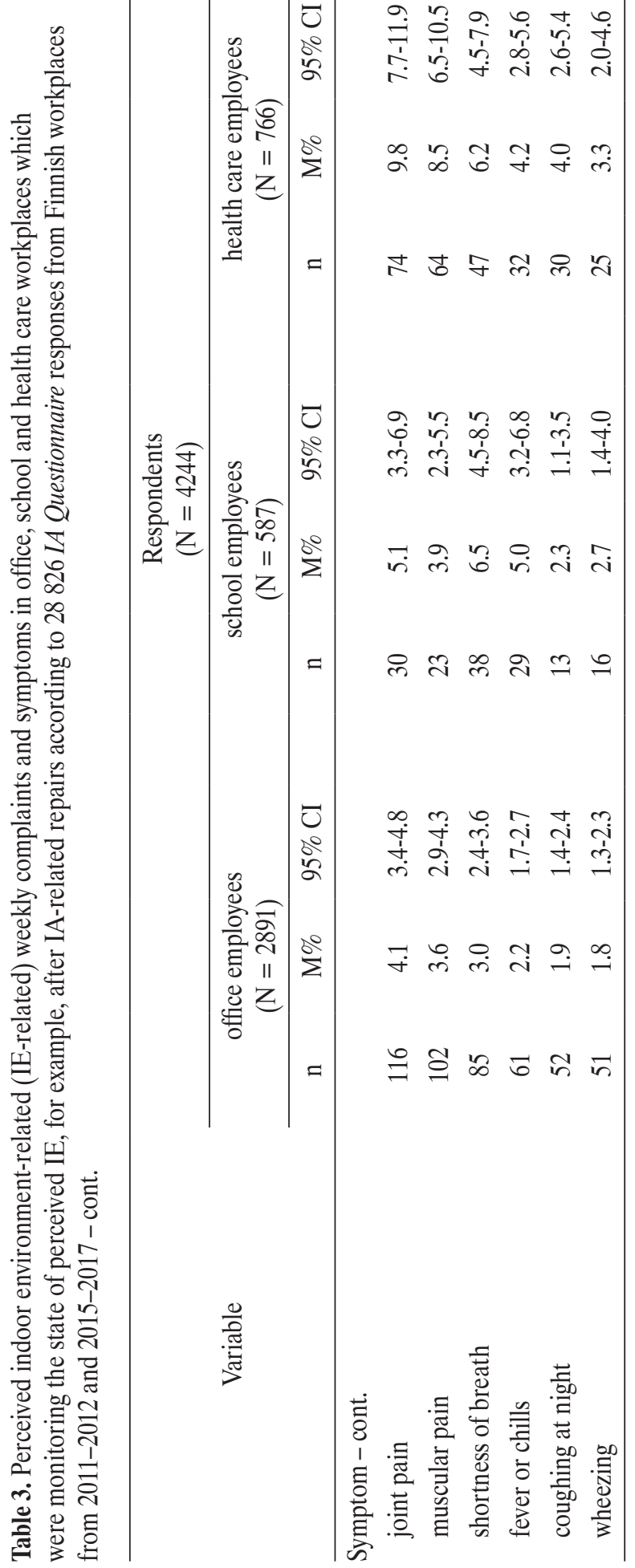

hoarse or dry throat (19.2\%), fatigue (14.6\%), or feeling heavy-headed $(11.9 \%)$ than the health care and school employees (Table 1).

Table 2 shows the data on the distribution of perceived IErelated weekly symptoms. The mean values in Table 1 are within the range of 50th-75th percentile (Table 2).

Table 3 illustrates the percent mean values of employees' IE-related symptoms in workplaces that were monitoring the state of perceived IE, for example, after IA-related repairs. In addition, IE-related symptoms were common in these workplaces.

\section{Perceived psychosocial work environment and stress}

The school employees and health care employees perceived their work as more interesting and stimulating than the office employees (Table 4). The office employees (17.2\% of respondents) felt they often had too much work to do and reported this more often than the school $(13.9 \%)$ or the health care employees $(16.6 \%)$ (Table 4$)$. The school employees (34.6\% of respondents) were able to influence their working conditions more often than the health care employees (27.5\%) (Table 4). The health care employees $(77.7 \%$ of respondents) felt that they received help from their fellow employees in their work more often than the office $(72.7 \%)$ and school $(73.3 \%)$ employees (Table 4). The office employees (3.6\% of respondents) most often experienced "very much" stress in their work. The health care workers $(17.7 \%$ of respondents) most often reported "not at all" being stressed in their work (Table 4).

Table 5 shows the data on the distribution of perceived psychosocial work environment and stress. The mean values in Table 4 mostly fall within the range of 50th-75th percentile (Table 5).

\section{DISCUSSION}

The data used in the study were extensive and described the perceived IA situation in office, school and health 
care environments in Finland very well. The standardized IA Questionnaire and its use are well established, which increases the reliability of the study. The present study enabled the authors to compare the differences between employees' IE-related symptoms, environmental complaints and psychosocial work environments in office, school and health care environments. The previous Finnish study, and the reference values for non-industrial workplaces and hospital environments, which were created through IA Questionnaires, were from 2004 and 2008 [1,15,21]. This study adds to the information provided by the previous study. The results of this study show that perceived IE-related symptoms and environmental complaints in health care environments have changed since the earlier FIOH study results in 2008 [1]. In addition, the authors found differences between the prevalence of IE-related complaints and symptoms among the employees in office, school and health care environments.

In the offices, the environmental complaints made most often referred to stuffy air, dry air, insufficient ventilation, draft and unpleasant odors. The most common symptoms were irritated/runny nose, irritation of the eyes, hoarse throat, fatigue and feeling heavy-headed. These most frequently perceived symptoms and environmental complaints have also been commonly found in other studies $[12,13,21]$.

In health care environments, the perceived environmental complaints had increased noticeably since FIOH's earlier study results and reference values in 2008 [1]. The environmental complaints most often addressed were stuffy air, dry air, insufficient ventilation, unpleasant odors and mould odor. These environmental complaints were also the most common complaints in FIOH's earlier study [1]. Environmental complaints about stuffy air, unpleasant odors, dry air and dust or dirt also found to be common in other studies [29]. Notably, noise was no longer experienced so much in hospital environments, but complaints of mould odor were higher in number than before.
The most often perceived symptoms were irritated/runny nose, irritation of the eyes, hoarse throat, fatigue and feeling heavy-headed. These perceived symptoms also found to be common in FIOH's earlier study [1] and other studies [2]. The prevalence of the symptoms and environmental complaints had both increased.

School employees' environmental complaints most often addressed stuffy air, insufficient ventilation, noise, dry air, and dust or dirt. Notably, noise was complained about much more often in schools than in office or health care environments. The most often perceived symptoms were hoarse throat, irritated/runny nose, fatigue, feeling heavyheaded, and irritation of the skin on the hands. Other studies $[23,26,30]$ have also found these perceived environmental complaints [23] and symptoms [26,30] to be common.

The employees in health care environments more often regarded their work as interesting and stimulating; they had fewer situations with too much work, and more possibilities to influence their working conditions than in FIOH's 2008 study [1]. In some respects, similar trends can be found in Statistics Finland's Quality of Work Life Survey 2013 [7]. This nationwide survey showed that wage and salary earners' general satisfaction with their current jobs, and especially with the content of their tasks, social relations and the ability to influence the workplace, had increased since 2008, whereas experiences of time pressure had eased during the studied period.

One interesting aspect in the authors' results was that although the office employees found their work less interesting, more often had too much work and experienced slightly more stress than the other study groups, they nevertheless reported less environmental discomfort and fewer symptoms than the school and health care employees. This seems to contradict the results of earlier studies, which have reported significant associations between the psychosocial environment and both IE-related complaints and symptoms [15,17]. Further studies should pay attention to this issue. 


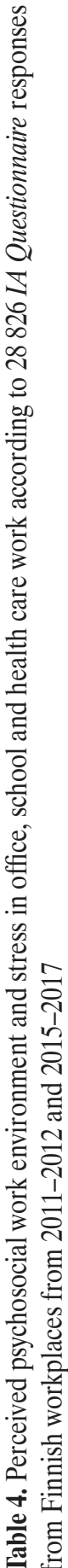

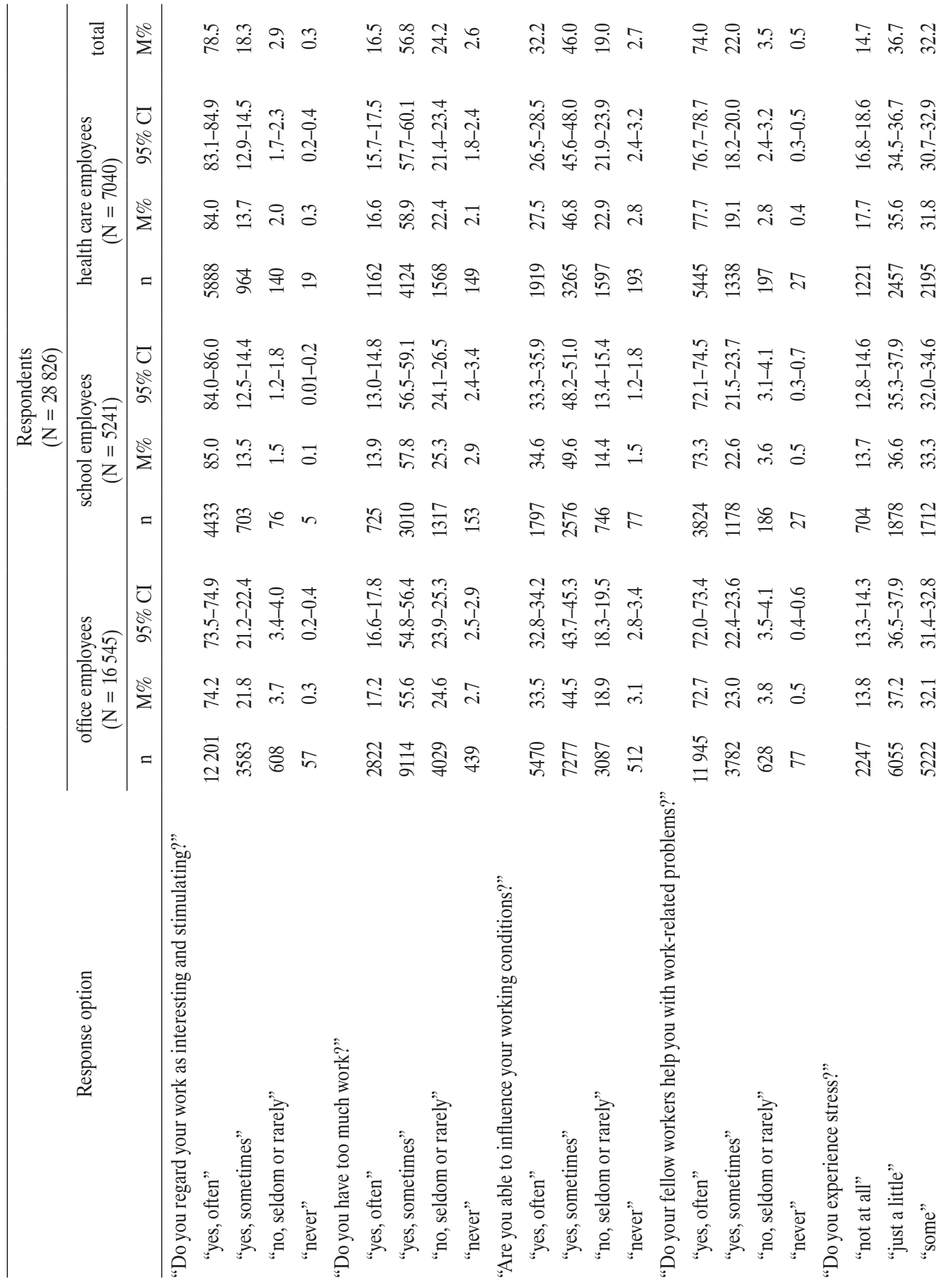




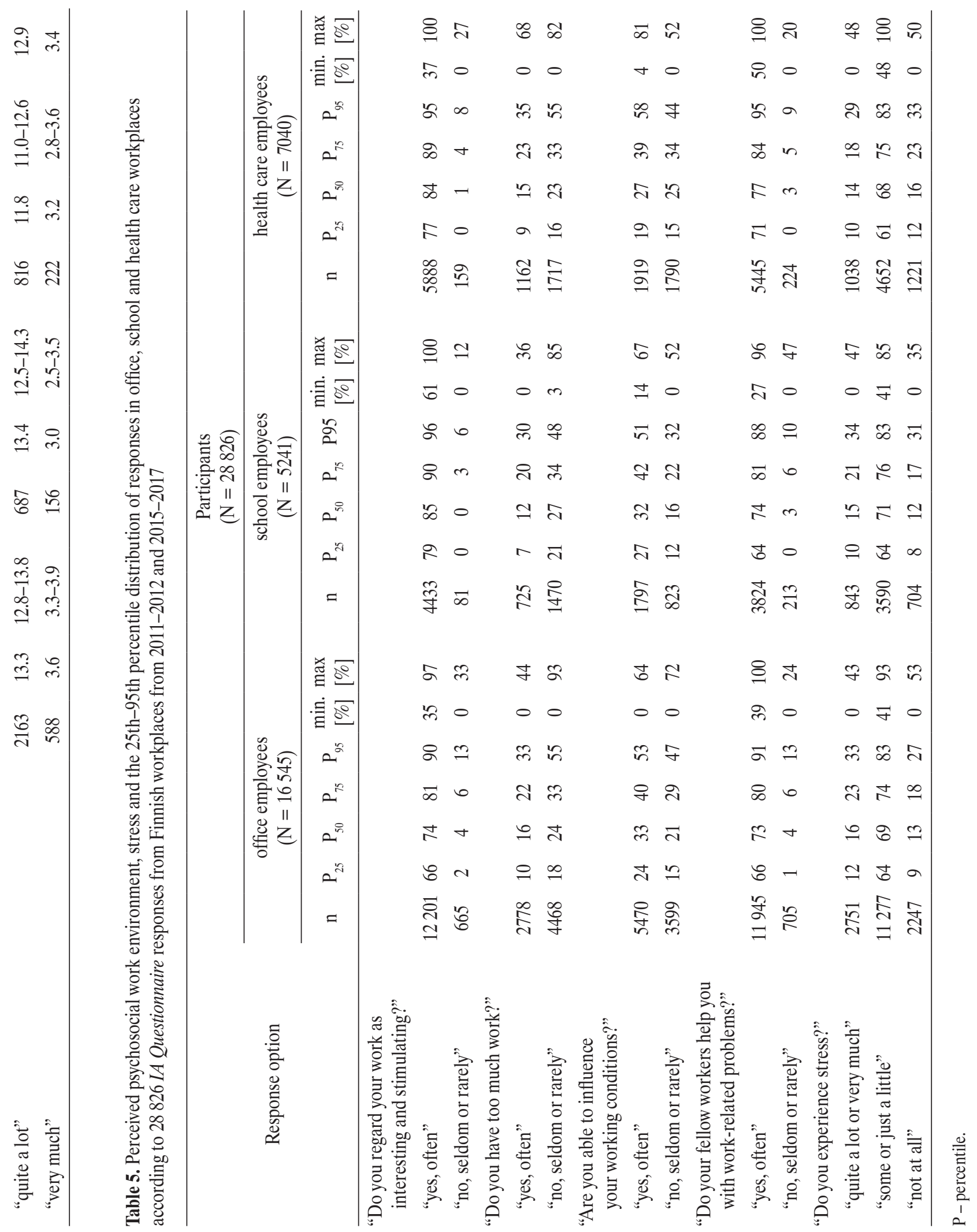


In this study, the authors present both the distribution and mean values of the questionnaire results. The examination of the distribution values was justified because 59\% of the responses were from workplaces with suspected IErelated problems. The authors formulated a hypothesis that complaints and symptoms would be more common in the overall data, in which $59 \%$ of the workplaces had suspected IE-related problems, than in the data from the subgroup of workplaces that were monitoring perceived IE. However, contrary to the authors' hypothesis, IE-related complaints and symptoms were also common in the subgroup.

Buildings and spaces, the factors affecting IA, people's subjective and individual differences, and their experience of the psychosocial work environment vary [8], making it difficult to define unambiguous reference values for interpreting IA Questionnaire. Instead of exact reference values, comparing the results of Örebro $M M-40$-based questionnaire with the distributions and mean values of the results of this study may be more informative for those solving IE-related problems. The reported IE-related complaints and symptoms with values of $<25$ th- 75 th percentile may represent workplaces that are unlikely to require further surveys (e.g., building investigations, occupational health service surveys). The reported IE-related complaints and symptoms with values of 75 th percentile $\rightarrow 95$ th percentile, in turn, may represent workplaces that need further inspections.

The presented distribution and mean values also enable the analysis of the psychosocial work environment at the workplace and the evaluation of possible effects on symptoms and complaints. Furthermore, the presented distribution and mean values might relate the results to other workplaces when interpreting Örebro MM-40-based questionnaire results and solving IE-related problems. This might increase the understanding that questionnaire results are influenced by many factors and that each workplace, situation and human experience is different.
The measures required at each workplace should always be evaluated from many perspectives and the results of IA Questionnaires are only a part of IE problem-solving. The present study shows that perceived IE varies according to work environments and that IE experiences have changed since earlier study results. Therefore, it is also recommendable to use the present results as new reference data to interpret Örebro MM-40-based questionnaire results in offices, schools and health care workplaces in Finland. The authors' study has some limitations. The data contained only self-reported IA Questionnaires results and the authors had no information on, for example, the workplace buildings and their condition or the current situation of the work organizations. The information on possible IE-related problems was based on the workplace's own assessment. Moreover, there was no information on the reasons why the workplaces that were monitoring the state of perceived IE were doing so. In addition, the questions concerning the psychosocial work environment in the Örebro $M M$-40-based questionnaire were quite limited. The questionnaire did not include, for instance, factors such as organizational changes and questions concerning leadership. It was not possible to assess different causal relationships in this study. It was also impossible, due to limitations of the data, to establish why the perceived IErelated symptoms and environmental complaints differed between the office, school and health care environments. The school category included different types of school environments, such as elementary schools and universities. In addition, 59\% of the responses were from workplaces with suspected IE-related problems. The perceived environmental complaints and symptoms were probably slightly higher than in a random sample.

Future studies should assess the relationship between symptoms and perceived environmental complaints, as well as between the IAQ and symptoms and environmental complaints. Further studies of the psychosocial environment are needed which address both IE-related complaints and symptoms. Studies should also assess whether 
individual factors can explain the symptoms, environmental complaints, and perceived psychosocial work environment. It would also be interesting to determine whether the workplace is private or public, which may partly be associated with some IE-related complaints.

\section{CONCLUSIONS}

There are differences between perceived IE in office, school and health care environments. Most of the perceived IE-related symptoms and environmental complaints had increased in health care environments since the earlier study results of the 2000s. The office employees' perceptions of psychosocial work environment remained fairly unchanged whereas the health care personnel more often assessed their psychosocial environment as positive compared to earlier findings.

Instead of exact reference values, comparing the results of IA Questionnaires with the distributions and mean values of the results of this study may be more informative for those striving to solve IE-related problems. The presented distribution and mean values of perceived symptoms, environmental complaints and psychosocial work environment might help to relate the results to other workplaces when interpreting IA Questionnaire results and solving IE-related problems. The reported IE-related complaints and symptoms with values within the range of $<25$ th-75th percentile may represent workplaces that are unlikely to require further surveys (e.g., building investigations, occupational health service surveys), and the reported IErelated complaints and symptoms with values of 75 th percentile $\rightarrow$ 95th percentile may represent workplaces that need further investigations.

The presented distribution and mean values of perceived symptoms, environmental complaints and psychosocial work environment might help to relate results to other workplaces when interpreting Örebro MM-40-based questionnaire results and solving IE-related problems. This, in turn, might increase the understanding that IA Question- naire results are influenced by many factors and that each workplace, situation and human experience is different. Notably, IA Questionnaires are only a part of IE problemsolving.

The results presented can be used as new reference material when interpreting Örebro MM-40-based questionnaire results in office, school and health care environments.

\section{ACKNOWLEDGMENTS}

The authors acknowledge the contribution of Sanna Lappalainen and Outi Fischer.

\section{REFERENCES}

1. Hellgren U-M, Palomaki E, Lahtinen M, Riuttala H, Reijula K. Complaints and symptoms among hospital staff in relation to indoor air and the condition and need for repairs in hospital buildings. Scand J Work Environ Health. 2008;(4):58-63.

2. Rautiainen P, Hyttinen M, Ruokolainen J, Saarinen P, Timonen J, Pasanen P. Indoor air-related symptoms and volatile organic compounds in materials and air in the hospital environment. Int J Environ Health Res. 2019;29(5):479-88, https://doi.org/10.1080/09603123.2018.1550194.

3. Mandin C, Trantallidi M, Cattaneo A, Canha N, Mihucz VG, Szigeti T, et al. Assessment of indoor air quality in office buildings across Europe - The OFFICAIR study. Sci Total Environ. 2017;579:169-78, https://doi.org/10.1016/j.scitotenv. 2016.10.238.

4. Sakellaris IA, Saraga DE, Mandin C, Roda C, Fossati S, De Kluizenaar Y, et al. Perceived Indoor Environment and Occupants' Comfort in European "Modern" Office Buildings: The OFFICAIR Study. Int J Environ Res Public Health. 2016;13(5):444, https://doi.org/10.3390/ijerph13050444.

5. Haverinen-Shaughnessy U, Borras-Santos A, Turunen M, Zock J-P, Jacobs J, Krop EJM, et al. Occurrence of moisture problems in schools in three countries from different climatic regions of Europe based on questionnaires and building inspections - the HITEA study. Indoor Air. 2012;22(6):457-66, https://doi.org/10.1111/j.1600-0668.2012.00780.x. 
6. Humphreys MA. Quantifying occupant comfort: are combinedindices of theindoorenvironmentpracticable? BuildRes Inf. 2005;33(4):317-25, https://doi.org/10.1080/0961321050 0161950 .

7. Statistics Finland (OFS). [Quality of work life] [e-publication]. Helsinki: Statistics Finland; 2014 [cited 2019 Aug 7]. Available from: http://www.stat.fi/til/tyoolot/2013/tyoolot_ 2013_2014-11-26_tie_001_fi.html.

8. Brauer C, Mikkelsen S. The influence of individual and contextual psychosocial work factors on the perception of the indoor environment at work: a multilevel analysis. Int Arch Occup Environ Health. 2010;83(6):639-51, https://doi. org/10.1007/s00420-010-0511-9.

9. Tähtinen K, Lappalainen S, Karvala K, Lahtinen M, Salonen H. Probability of Abnormal Indoor Air Exposure Categories Compared with Occupants' Symptoms, Health Information, and Psychosocial Work Environment. Appl Sci. 2018;9(1):99, https://doi.org/10.3390/app9010099.

10. Carrer P, Wolkoff P. Assessment of Indoor Air Quality Problems in Office-Like Environments: Role of Occupational Health Services. Int J Environ Res Public Health. 2018;15(4):741, https://doi.org/10.3390/ijerph15040741.

11. Frontczak M. Quantitative relationships between occupant satisfaction and satisfaction aspects of indoor environmental quality and building design. Indoor Air. 2012;22(2):119-31, https://doi.org/10.1111/j.1600-0668.2011.00745.x.

12. Magnavita N. Work-related symptoms in indoor environments: a puzzling problem for the occupational physician. Int Arch Occup Environ Health. 2015;88(2):185-96, https:// doi.org/10.1007/s00420-014-0952-7.

13. Bluyssen PM. Self-reported health and comfort in 'modern' office buildings: first results from the European OFFICAIR study. Indoor Air. 2016;26(2):298-317, https://doi. org/10.1111/ina.12196.

14. Kim J, de Dear R, Cândido C, Zhang H, Arens E. Gender differences in office occupant perception of indoor environmental quality (IEQ). Build Environ. 2013;70:245-56, https://doi.org/10.1016/j.buildenv.2013.08.022.
15. Lahtinen M, Sundman-Digert C, Reijula K. Psychosocial work environment and indoor air problems: a questionnaire as a means of problem diagnosis. Occup Environ Med. 2004;61(2):143, https://doi.org/10.1136/oem.2002.005835.

16. Finell E, Seppälä T. Indoor air problems and experiences of injustice in the workplace: A quantitative and a qualitative study. Indoor Air. 2018;28(1):125-34, https://doi. org/10.1111/ina.12409.

17. Runeson R, Wahlstedt K, Wieslander G, Norbäck D. Personal and psychosocial factors and symptoms compatible with sick building syndrome in the Swedish workforce. Indoor Air. 2006;16(6):445-53, https://doi.org/10.1111/j.16000668.2006.00438.x.

18. Andersson K. Epidemiological Approach to Indoor Air Problems. Indoor Air. 1998;8(S4):32-9, https://doi.org/10. 1111/j.1600-0668.1998.tb00005.x.

19. Nissilä J-J, Savelieva K, Lampi J, Ung-Lanki S, Elovainio M, Pekkanen J. Parental worry about indoor air quality and student symptom reporting in primary schools with or without indoor air quality problems. Indoor Air. 2019;29(5):865-73, https://doi.org/10.1111/ina.12574.

20. World Health Organization. Dampness and Mould - WHO Guidelines for Indoor Air Quality. Geneva: The Organization; 2009 [cited 2019 Aug 7]. Available from: http://www. euro.who.int/_data/assets/pdf_file/0017/43325/E92645. pdf?ua $=1$.

21. Reijula K, Sundman-Digert C. Assessment of indoor air problems at work with a questionnaire. Occup Environ Med. 2004;61(1):33-8.

22. Azuma K, Ikeda K, Kagi N, Yanagi U, Osawa H. Evaluating prevalence and risk factors of building-related symptoms among office workers: Seasonal characteristics of symptoms and psychosocial and physical environmental factors. Environ Health Prev Med. 2017;22(1):38, https://doi.org/10.1186/ s12199-017-0645-4.

23. Järvi K, Vornanen-Winqvist C, Mikkola R, Kurnitski J, Salonen $\mathrm{H}$. Online questionnaire as a tool to assess symptoms and perceived indoor air quality in a school environment. 
Atmosphere. 2018;9(7):270, https://doi.org/10.3390/atmos90 70270.

24. Angelon-Gaetz KA, Richardson DB, Marshall SW, Hernandez ML. Exploration of the effects of classroom humidity levels on teachers' respiratory symptoms. Int Arch Occup Environ Health. 2016;89(5):729-37, https://doi.org/10.1007/ s00420-016-1111-0.

25. Park JH, Schleiff PL, Attfield MD, Cox-Ganser JM, Kreiss $\mathrm{K}$. Building-related respiratory symptoms can be predicted with semi-quantitative indices of exposure to dampness and mold. Indoor Air. 2004;14(6):425-33, https://doi. org/10.1111/j.1600-0668.2004.00291.x.

26. Sahakian NM, White SK, Park J-H, Cox-Ganser JM, Kreiss K. Identification of Mold and Dampness-Associated Respiratory Morbidity in 2 Schools: Comparison of Questionnaire Survey Responses to National Data. J Sch Health. 2008;78(1):327, https://doi.org/10.1111/j.1746-1561.2007.00263.x.
27. Patovirta RL, Husman T, Haverinen U, Vahteristo M, Uitti JA, Tukiainen $\mathrm{H}$, et al. The remediation of mold damaged school--a three-year follow-up study on teachers' health. Cent Eur J Public Health. 2004;12(1):36-42.

28. Elo A-L, Leppänen A, Jahkola A. Validity of a single-item measure of stress symptoms. Scand J Work Environ Health. 2003(6):444-51, https://doi.org/10.5271/sjweh.752.

29. Loupa G, Fotopoulou S, Tsagarakis KP. A tool for analysing the interdependence of indoor environmental quality and reported symptoms of the hospitals' personnel. J Risk Res. 2017;20(5):678-91, https://doi.org/10.1080/13669877.2015.11 19182.

30. Claudio L, Rivera GA, Ramirez OF. Association Between Markers of Classroom Environmental Conditions and Teachers' Respiratory Health. J Sch Health. 2016;86(6):44451, https://doi.org/10.1111/josh.12398.

This work is available in Open Access model and licensed under a Creative Commons Attribution-NonCommercial 3.0 Poland License - http://creativecommons.org/ licenses/by-nc/3.0/pl/deed.en. 